CAE Working Paper \#06-01

\title{
Coercion, Contract and the Limits of the Market
}

by

Kaushik Basu

January 2006 
January 3, 2006

\title{
Coercion, Contract and the Limits of the Market
}

\author{
Kaushik Basu \\ Department of Economics \\ Cornell University \\ Ithaca, New York 14853 \\ Email: kb40@cornell.edu
}

\begin{abstract}
It is a widely accepted principle of economics that if two or more adults voluntarily agree to a contract or an exchange that has no negative fall-out on others, then the government should not stop such a contract. This is often called the 'principle of free contract' (PFC). There is a body of writing in economics which upholds the PFC. Yet, this ubiquitous principle is ill-defined and full of ambiguities. For instance, since it refers to voluntary choice, its proper use presumes an understanding of what is 'voluntary' and, therefore, also, of what is coercive. What is ironic is that, while philosophers and legal scholars have debated and analyzed these concepts and the validity of the principle of free contract, there is very little discussion of these in economics, even though so much of economics is founded on this principle. This has caused a lot of policy confusion. The aim of this paper is to construct general rules for when we may violate the PFC. The argument is constructed within the Paretian framework. Hence, the violation of the PFC is not justified by appeal to deontological ethics or non-welfarist criteria. This is not an easy task since the principle of free contract is often viewed as a rule that is a derivative of the Pareto principle.
\end{abstract}

Key words: Coercion, voluntary choice, contracts, markets, government intervention.

Acknowledgements: This paper is based on my Colin Clark Lecture, 2004, held at the Australasian Meetings of the Econometric Society, Melbourne, and a seminar presentation at the Conference on the Philosophical Aspects of Social Choice Theory and Welfare Economics, at the University of Caen, 20 June, 2005. The paper has existed in the form of notes and sketches, but remained essentially unwritten till recently. Over this time I have accumulated indebtedness to a large number of colleagues and friends. At the certainty of omission, I would like to mention Geir Asheim, Abhijit Banerjee, Kuntal Banerjee, Alaka Basu, Hyejin Ku, Wulf Gaertner, Prasanta Pattanaik, John Roemer, Joshua Teitlebaum and Amartya Sen. 


\section{Coercion, Contract and the Limits of the Market}

\section{Principle of Free Contract}

In 1995, soon after I moved to the U.S., I got a letter from a lawyer in California requesting me to write a letter to a judge of the California Supreme Court in support of his client. Not being sure of the ethics of such matters, let me not reveal names. His client, Mr. X, had been approached by an entrepreneur, Mr. R, for a loan of $\$ 500,000$ in order to open a restaurant. They agreed to an annual interest rate of $12 \%$ and a schedule of repayment in installments. For some time $\mathrm{R}$ paid him in accordance with the repayment schedule; but then he began to default. After waiting for a while, $\mathrm{X}$ decided to take R to court for breach of contract. The case was proceeding well and seemingly in favor of X, when R's lawyers discovered that a $12 \%$ interest rate was a violation of the statutory limit on interest rates prevalent in California at that time, which set an upper bound at $11 \%$ for interest rates on loans. This was used by R's lawyers to argue that the entire contract was null and void and, therefore, R should pay no interest; moreover, by this argument, he had over paid $\mathrm{X}$ and so in fact ought to get money back from $\mathrm{X}$.

It was at this stage that $\mathrm{X}$ 's lawyer decided to seek the support of some economists (knowing, I suppose, our profession's proclivity in such matters). What I wrote to the Judge of the California Supreme Court was, in a nutshell, this. What the law says has to be followed, but how severely a violation of the law has to be redressed often depends on our view of how reasonable the law happens to be. And I went on to argue that in this case the statutory interest law in California was quite unreasonable. When an adult, especially someone who is business savvy, agrees to take a loan with a $12 \%$ interest rate and another person agrees to lend money at 12\% interest rate, presumably both expect to be better off through this exchange. And if there is no reason to expect this to have negative fall-outs on others, then no one should stop such a contract. Indeed, the ability among adults to freely sign contracts and rely on them is the bedrock of a vibrant, modern economy. Business, enterprise and progress are made possible by such 
contracts and, equally, progress gets stymied if such contracts are disallowed. The rest of what I wrote to the judge is not relevant here.

Some months later I met an economist who had received the same request from the lawyer and had also written to the judge. On comparing notes we discovered that we had taken almost exactly the same line. On consideration, this is not so surprising. It is a widely accepted principle of economics that if two or more sentient adults voluntarily agree to a contract or an exchange, which has no negative fall-out on those uninvolved in the contract, then the government should not stop such a contract. This is often called the 'principle of free contract' (see Basu, 2003, for discussion) - PFC, in brief.

Though this paper will be concerned with the exceptions to this principle, I want to stress its significance in enabling a market economy to function effectively. In the US this principle is often viewed as protected by the Fourteenth Amendment (1868) to the Constitution. The freedom of contract was often alluded to as a "property right" and there are celebrated cases, such as Lochner v. the New York State, 1905, where any effort to curtail work hours or legislatively raise wages was struck down by the courts as being in violation of the freedom of individuals to sign contracts as they wished. Indeed, it is arguable that one critical ingredient in the outstanding performance of the American economy since the late nineteenth century is the faith the U.S. courts evinced in the principle of free contract, even though, as we shall presently see, this is a principle that can be overdone. There is a body of writing in economics which upholds the PFC (see, eg., Friedman, 1962) and, more significantly, there is widespread, unwritten acceptance of this principle ${ }^{1}$.

Despite the value of this principle, what is worrying is that its terms are, on reflection, ill-defined and has its share of ambiguities. For instance, since it refers to voluntary choice, its proper use presumes an understanding of what is 'voluntary' and, therefore, also, of what is coercive. Yet these are concepts ill-understood in economics. What is ironic is that, while philosophers and legal scholars have debated and analyzed these concepts and the validity of the principle of free contract, there is very little

\footnotetext{
${ }^{1}$ While economists typically value this principle as a critical instrument for economic progress and efficiency, one can think of other, philosophical justifications for adhering to this principle, such as equating a contract with a promise and maintaining, a priori, that it is immoral for promises to be broken (see Kaplow and Shavell, 2002, Chapter 4, for discussion of some of these alternative justifications.)
} 
discussion of these in economics, even though so much of economics is founded on this principle.

This has caused a lot of policy confusion. On the one hand, we find wanton violation of this principle by governments and bureaucrats. On a variety of matters governments specify terms of contracts exogenously. In India, any firm that employs over 50 laborers has pre-specified terms for laying-off workers spelled out in the Industrial Dispute's Act, 1947; and any firm employing more than 100 laborers has to have prior permission from the government before it can lay off workers. A contract voluntarily entered into by an entrepreneur and a worker that specifies terms of disengagement which are different from what the law specifies (e.g. the salary will be very high but the firm can ask the worker to quit with no prior notice and no severance pay) will be dismissed by the courts as invalid in the same way that the loan contract in California was considered null and void. So, if after having signed the contract, the worker or the employer later reneges on it, the other side will not have any recourse to the law. And knowing this, people in India do not typically sign such contracts. Many economists have argued (and I find myself in agreement with them on this) that the pervasive failure to respect the principle of free contract has harmed the Indian economy, since entrepreneurs hesitate to start up businesses in which demand is volatile (for instance, fashion garments) and require periodic hiring and laying off of workers.

There are mainstream economists and some legal scholars who take this line of argument to an extremity, and do not recognize that the PFC can have any exceptions. But it is not difficult to find examples where a majority would feel uncomfortable adhering to the principle of free contract. Here are some examples.

In 1903 there was the celebrated case, The Port Caledonia and the Anna, in which a vessel that got into a dangerous crisis at sea sought help from a tug (Wertheimer, 1996). The master of the tug asked for $£ 1,000$ (an astronomical sum at that time) and made it a 'take it or leave it' offer. The master of the vessel, unsurprisingly, accepted the offer, but later went to court. The court declared the 'contract' or agreement void and ruled that the vessel master needed to pay $£ 200$. Evidently, the court’s ruling violated the PFC.

Second, suppose a firm puts up a sign outside the personnel office which makes it clear to new workers that the firm pays its workers excellent salaries, gives generous 
health benefits, time off for vacations, but reserves the right to sexually harass its workers. It then leaves it to workers to freely decide if they wish to work for this firm. It would seem, if some workers choose to do so, then under the PFC the state has no business stopping them. So should government allow firms to offer contracts of the above kind to workers? ${ }^{2}$ Presumably many firms will then have 'standard forms' whereby they will make workers relinquish the right not to be sexually harassed ${ }^{3}$. But under the PFC we should not object to this.

Third, suppose a poor worker wants to declare himself a slave to a rich landlord in order to have a regular supply of food and the landlord sees this as an opportunity to add another slave to his retinue. Should such voluntary slavery be permitted? Prominent thinkers, including those otherwise committed to the PFC, have felt uncomfortable saying yes to this. John Stuart Mill (1848) was troubled by this and took cover by taking the rather arbitrary line that very long-run contracts should not be allowed, because people are not able to judge their own well-being over very long stretches of time. ${ }^{4}$

There are many other examples. Should we look the other way if a firm exposes workers to large health hazards as long as this is made clear to the workers in advance and they are not coerced into accepting the job? Is it all right for corporations in export processing zones to demand that any worker who wishes to work there has to give up his or her right to join trade unions? This is a practice that is becoming increasingly common in countries eager to woo multinational corporations to their shores. Should we not argue that, by the PFC, this is fine since no one is forced to work in an export processing zone.

Interestingly, it was common practice in the US till the 1930s for firms to make workers sign a standard form relinquishing their right to join trade unions before giving them employment. This was called a “yellow dog contract”. But it was 'felt' that this was wrong and by the Norris-La Guardia Act or the Anti-Injunction Bill, 1932, yellow dog contracts were declared to be illegal in the U.S. ${ }^{5}$

\footnotetext{
2 This is one of the questions raised in Basu (2003).

3 The 'standard form', as with yellow-dog contracts, discussed below, or with boilerplate contracts or contracts of adhesion, has been a subject of some debate. Wertheimer (1996) has discussed this in the context of Henningsen and Bloomfield Motors, 1996. See also, Korobkin (2003), and Choi and Gulati (2005).

${ }^{4}$ He took a more sophisticated line in Mill (1859) to rule out voluntary slavery contracts. For an interesting discussion of long-run child labor contracts, see Iversen (2004).

${ }^{5}$ For more examples see Kanbur (2004) and Satz (2004).
} 
The trouble is that most of the time we react in an ad hoc fashion to these troubling questions. We outlaw some practices and allow others but do not have clear rules of why and under what circumstances is it all right to violate the PFC. Without some such general rules, we however have a handicap, when we try to advise others. When a Third World country declares that no one has the right to sell her land, we rush to say that this is foolish because if someone wants to sell and someone wishes to buy and there is no negative externality on an uninvolved third party (in other words the conditions of the PFC hold) then we ought not to ban such exchanges. To do so is to harm the economy's growth and efficiency. But if the Third World bureaucrat then turns round and asks how can we in that case justify the Norris-La Guardia Act, we are short of a good answer, and often cite arbitrary non-welfarist objectives ${ }^{6}$.

One widely used justification for disallowing free contracts is when this occurs between parties of asymmetric power. Thus, for instance, in the Henningsen v. Bloomfield Motors, 1960, case the court disallowed the standard form contract by arguing that (Wertheimer, 1996, p.45) "freedom of contract is most at home when a contract is the result of free bargaining of parties ... who meet each other on a footing of approximate economic equality" (my italics). This widely used argument is however invalid. If contracts signed between the rich and the poor are not treated as valid by virtue of power asymmetry, the rich will refuse to sign contracts with the poor (knowing that the courts are likely to overturn them). Hence, the poor will tend to get excluded from the market. They will not be able to get loans easily or be able to sign so many other kinds of contracts one needs to get ahead in life. Hence, the asymmetry of power cannot in itself be construed as reason for violating the PFC.

The aim of this paper is to see how we can construct general and appealing rules for where we may violate the PFC, while adhering to the basic axiom of the 'Pareto principle'. Hence, the route of using some deontological principle or some non-welfarist criterion to put aside Pareto is not a line that is permitted here. This is not an easy task

\footnotetext{
${ }^{6}$ It is not that I wish to deny the use of all non-welfarist moral principles. I simply maintain that nonwelfarist principles should not be used to violate the Pareto principle. We may use non-welfarist criteria to choose between two Pareto non-comparable states (Basu, 2003). Hence, this approach, despite the centrality it grants to welfarism, is compatible with the approach of individual rights, as in Sen (1982). Also, giving lexicographic primacy to the Pareto principle and using possible non-welfarist criteria only after that enables us to escape possible logical contradictions (Kaplow and Shavell, 2001).
} 
since the principle of free contract is often viewed as a rule that is in fact a derivative of the Pareto principle.

It is worthwhile clarifying the meaning of the Pareto principle (PP). For this it is useful to first define a 'Pareto improvement'. A 'Pareto improvement' is a change, which leaves at least one person better off and no one worse off. The PP can then be described as a normative rule that says that a Pareto improvement is socially desirable and so should not be thwarted by the state or anybody for that matter (excepting when it is selfcontradictory in the sense that its repeated use leads to a Pareto inferior state - that is, a state from which to go back to the original state would constitute a Pareto improvement or a Pareto non-comparable state). The qualifier within parenthesis can be ignored for now; its significance will become evident later.

The PP is not without its critics ${ }^{7}$ but I am inclined to treat it as valid. Hence, my general strategy here will be to uphold PP and argue that this is not synonymous with the PFC; and to look for justifiable violations of the PFC within the class of cases where the PP holds. In other words, I am seeking principles which allow us to disregard the PFC in situations where to uphold the PP does not mean upholding the PFC. If this sounds abstract, I would seek the reader's patience only briefly, since the meaning of this will be made clearer soon.

One spurious confusion that occurs occasionally in the literature and is best got out of the way at the outset is caused by confounding the PP with another related principle which may be called the Pareto Optimality principle (POP), which says that, if an outcome is Pareto optimal, ${ }^{8}$ then it is desirable (and so should not be stopped by the state).

Not only are PP and POP distinct, but I find the former an attractive normative axiom and the latter unacceptable. For one, if we wish to pass any judgement on distributional matters, such as wanting to shun extreme inequality, then we have to reject the Pareto optimality principle (Sen, 1973). Another example that illustrates the moral

\footnotetext{
${ }^{7}$ Sen, (1970a, 1970b), for instance, demonstrates that if we wish to hold on to even a minimal form of individual liberty, we may be compelled to abandon the Pareto Principle. See Gaertner, Pattanaik and Suzumura (1992) for further discussions of this question. In Basu and Mitra (2003) we demonstrate that the Pareto Principle may conflict with a minimal equity axiom. For a general discussion of the limitations of the Pareto principle, see Farber (2005).
} 
separateness of POP and PP is seen with the case of torture. If a torturer feels pleasure by torturing, then by the POP torture could be desirable. The state should not stop it. To see this suppose in a society only two states are available: $x$, where there is no torture and $y$ where person 1 tortures person 2. Since 1 is better off in $y$ than in $x$, it must be that $y$ is Pareto optimal and so it is a desirable outcome by the POP $^{9}$. Notice that the rejection of $y$ is permitted under the PP since between $\mathrm{x}$ and $\mathrm{y}$ neither is a Pareto improvement on the other (since 2 is better off under $\mathrm{x}$ ).

The main argument of this paper is presented in section 3, where I shall show that in a variety of situations the PP and the PFC do not give us the same prescription and so paves the way for rejecting the PFC while adhering to the PP. The other argument- to do with multiple equilibria--is more obvious and for that reason is discussed only briefly, in section 4. This paper also briefly discusses some actual problems of government intervention and illustrates contexts where the rules developed in sections 3 and 4 apply in practice. These practical applications are not an easy matter and, as of now, do not have ready answers to many questions. It can be shown that there are situations where child labor can be banned even in situations where no coercion is involved (Basu and Van, 1998). This is by the multiple equilibria argument. Likewise, contractual sexual harassment in the workplace should be banned by the argument of section 3. As for hazardous work and giving up trade union rights in export-processing zones, these are matters that remain to be analyzed. What this paper does is to outline normative rules that can be used to analyze them.

In brief, the position taken in this paper is that the principle of free contract is a good default rule, which is violated too often by governments. But, at the same time, it is not sacrosanct and there are good moral reasons, within the Paretian framework, which allow us to suspend the use of the PFC in some contexts. This is not too distant from the line taken by the so-called 'left libertarian school' (see Steiner, 1994; Vallentyne, 2000). To have self-ownership and the freedom to contract and to expect the contract to be

\footnotetext{
${ }^{8}$ An outcome is Pareto optimal if for every feasible change there is at least one person who becomes worse off.

${ }^{9}$ If torturers feel no innate pleasure from torturing but use it only to extract money or other benefits from the torturee, then even the POP would not justify torture. This is because a society in which torture occurs is Pareto dominated by one in which the same concessions that are earned through torture are earned
} 
enforced do not mean that all resources need to be carved out among individuals, nor do they mean that we have to abandon egalitarianism (Cohen, 1986; Otsuka, 1998). ${ }^{10}$

Section 2 deals with a prior matter. Recall that the PFC only talks about contracts, exchange and trade that are voluntarily entered upon. But what is a voluntary contract and, equivalently, what is coercion? I shall argue in the next section that the PFC is often invoked spuriously by mistakenly taking certain actions to be voluntary when they are not so. Though I do not succeed in giving a full definition of what is coercion (or what is

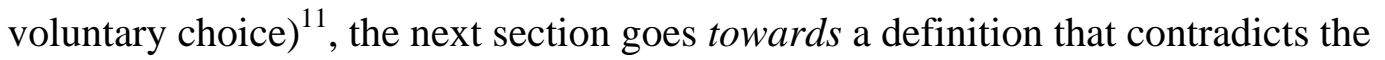
position taken by much of economics. It demonstrates that coercion is essentially a normative concept. Two observers can agree about the facts of a case but legitimately disagree about whether coercion has occurred. Thereafter, in the sections that follow, I shall proceed by putting aside the definitional problems, that is, by simply assuming that we all know what is voluntary and what is coercive.

\section{Coercion and Voluntariness}

In trying to understand coercion and voluntariness, the risk that many an analyst has succumbed to is that of falling into a tautological or near-tautological trap - of finding virtually all human behavior as examples of free choice or all behavior as illustration of coercive action. The conservative neoclassical economist often bends over backwards to show that virtually all choice is non-coercive. This is because, as Zimmerman (1981, p. 122) pithily puts it, “[S]ocialists and laissez-faire liberals alike [...] have embraced the conviction that coercion is prima facie morally wrong.” Hence, to admit coercion is to concede the need for government intervention. As Zimmerman puts it in the same page, "if capitalist wage bargains did involve coercion, that would be one moral strike against them.” However, it is equally possible to err on the other side, to jumping to conclude too easily that coercion has occurred.

without torture (see Basu, 2005 for discussion of this in the context of domestic violence). I am grateful to George Akerlof for drawing my attention to this.

${ }^{10}$ For a lucid essay that recognizes the importance of the free market but constrains it within the requirements of fairness and justice, see Sunstein (1997).

${ }^{11}$ Nor do I find a compelling definition in the existing large literature (mostly outside of economics): see, for instance, Nozick, 1969, 1974; Macpherson, 1973; Zimmerman, 1981; Cohen, 1987; Trebilcock, 1993). 
Suppose a worker chooses to work in a low-paid hazardous industry. Did he choose this voluntarily? The correct answer is: we cannot say; we need more information about the circumstances before we can pronounce on this. So let us add to the above description the fact that this person's only other option was to be unemployed, which would leave him abysmally poor. To some social scientists, this is enough information to be able to say: His was not a voluntary choice because, effectively, he had no choice, since being unemployed is not really something one chooses (Macpherson 1973). On the other hand, there is a liberal position, best exemplified in Nozick (1974) that would argue that if other agents acted voluntarily and within their rights, then the worker can be described as having chosen voluntarily and without coercion. This is also wrong but for more complex reasons.

Hence, I am arguing here that both these positions are flawed (which shows that, while my position will be Nozickian in some ways, it is distinct from that of Nozick). With the information we have thus far, strictly, we cannot say whether the worker was coerced or not. The qualifier, 'strictly', is important here, because if we did indeed have this much information and no more and we had to take a position on this, I would be inclined to treat this as a case of voluntary choice. Since the accompanying conditions that we need for this to be construed as coercion (as we shall presently see) seems empirically unlikely.

Those who jump to conclude that this is a case of coercion, usually take the view that the 'choice' of being unemployed is not a serious choice. They feel that no one should have to take a miserable job. But the mistake with this is its implicit tendency to assume that if "no one should have to take such a miserable job," then "someone taking such a job” must imply coercion. This and the opposite error of jumping to conclude that this is voluntary, curiously, can stem from the same basic mistake- the tendency to equate "having choice” with "not being coerced."

Since we do not have the advantage of having an undisputed definition of these terms, let me proceed from an example where we will, presumably, all agree, to other more complex cases, by analogy.

In 1971 when I was a student in Delhi I was mugged at knife point one winter evening on the Delhi University campus. Three men in shawls came up to me on an ill-lit 
road, and one of them whipped out a knife and asked me for my watch. It took me a few seconds to decide what I should do. I took off my watch and handed it over to the man with the knife (somehow I seem to recall I thanked him) and walked back to my dorm. The question is: Did I part with my watch voluntarily or under coercion?

Clearly, everybody will agree that this is coercion. If this is not coercion, then pretty much nothing is. But notice that this was not a situation of no choice. When the man pointed the knife at me and asked for my watch, he was giving me a choice: I could give him my watch or my life. I chose to keep my life. In fact, it was a bargain since mine was a cheap, unreliable watch. So having a choice cannot be equated with noncoercion.

It is depriving me of my right, namely, the right to both my watch and life that made it a case of coercion. Given that one's rights are a matter of morals, I would, unlike Zimmerman (1981) and like Nozick in his paper on coercion (Nozick, 1969), treat coercion as a moral concept. That is, what we think of as coercion depends on our notion of a moral baseline. This is quite distinct from the concept of coercion one encounters (admittedly only suggestively) in mainstream neoclassical economics. And all this is closely related to the PP, since the PP is all about Pareto improvements being approved. But as soon as we talk of an 'improvement,' a question arises "from where or from which moral baseline?” What I have just argued is that there may be ambiguities on this. It should be clear that the moral baseline is indeed a normative matter and is not simply a matter of one's average or expected or current utility level ${ }^{12}$.

Let us suppose I, knowingly, choose to go for an evening walk to a dangerous neighborhood. Assume that there is a half probability that I will come back safe, in which case (let us assume) I will have 100 utils of satisfaction, and half probability that I will lose everything - wallet, watch, clothes on me--, in which case I will have 0 utils. Hence, when I choose to go out for a stroll to that area I am choosing to have an expected utility of 50 utils. Of course, if I am robbed of everything, we will all agree that I have been coerced, since I am worse off than any reasonable benchmark, for instance, the expected

\footnotetext{
${ }^{12}$ An alternative way of viewing this is to say that we have a prior sense of the 'correct' assignment of property rights; and 'coercion' entails a forced (and therefore illegal) alteration of these property rights. To the extent that an assignment of property rights is a normative act, this interpretation is essentially the same
} 
utility that evening (of 50 utils). But suppose now that, instead, the mugger takes only my cheap watch, which has merely 40 utils of worth to me. So I return home with 60 utils. Note that this is a little more than the expectation I had at the start of my voluntary stroll. Would we now say that I parted with my watch voluntarily? Most of us would disagree with this. The reason is that most of us treat the baseline of utils not to be my expected utility level of 50 but 100, that is, with everything intact. Even though my choice to go for that risky stroll was voluntary, the fact of losing my watch is not.

This point of view is bolstered further and also made more complicated with an example of triadic interaction, which shows that everyone staying within their rights (unlike the mugger in the above example who had no right to my watch or life) is not enough to guarantee voluntariness and non-coercion. This is a more controversial point and a by-product of models of triadic interaction that have been used to study agrarian and international relations ${ }^{13}$.

These models recognize that there are many contexts in reality where interaction between individuals or agents is non-dyadic, what happens between persons $\mathrm{i}$ and $\mathrm{j}$ can depend on what happens between i and k. By the Helms-Burton Act, for instance, the U.S. seeks to control Cuba by threatening to take action against other countries for trading with and investing in Cuba. Akerlof (1976) had argued with an elegant model how allowing for triadic interactions is critical to understanding caste-based relations.

Let me here consider the case of a village in which there is a landlord (1), a laborer (2) and a merchant (3). In Basu (2000) I had argued that what the landlord can extract from the laborer according to textbook models in economics, may be less than what he can extract in reality by using 'triadic threats', that is, by announcing that he will boycott trade with the merchant if the laborer turns down the landlord's offer and, despite that, the merchant trades with the laborer. Without going into the formalism, the essential argument is easy to see. If the threat were credible ${ }^{14}$, the worker would realize that to turn down the landlord's offer would mean losing out on not only what the landlord offers but also on what he was getting from the merchant. Knowing this, the landlord is able to

as the one described above. But given that property rights must here mean an assignment of rights over all possible actions, there is the possibility of ambiguity that is discussed below.

${ }^{13}$ See Akerlof, 1976; Deshpande, 1999; Basu, 2000; Naqvi and Wemhoner, 1995; Hatlebakk, 2002; Villanger, 2004, 2005. 
make an offer so that, by accepting it, the worker gets the same level of utility as (or maybe an epsilon more than) what he would get if he got nothing from the landlord and nothing from the merchant. And so the worker will accept this offer since it is as good as (or 0 better than) what his alternative is. In other words, by accepting the landlord's offer the worker gets negative utility-he loses whatever net value he was earning from his interaction with the merchant.

If we take the normative stance that the worker has the right to the level of utility he gets by interacting with the merchant, then we can see that the landlord's offer is akin to the mugger's offer, which makes the worker worse off than this moral benchmark. The greater complication here is that the landlord (unlike the mugger) is however not veering outside of what is within his right-namely, to trade with whoever he chooses - since the landlord simply announces circumstances in which he will interact with the merchant. By doing this he manages to coerce the worker ${ }^{15}$. And the worker, who gets a choice and exercises it and may therefore seem to have made a voluntary choice, ends up worse off than a significant moral benchmark and so could very reasonably be described as having been coerced.

This complicates the simplicity of our neoclassical analysis. Coercion can occur in more subtle ways. And what we often take to be voluntary may turn out not to be so on closer inspection. Hence, some cases of the PFC can be dismissed on the ground that the preconditions for using that principle, namely, that all choices be voluntary, are not satisfied.

With this cautionary tale, let us now move to domains where we have no reason to contest the voluntariness claim. Can we, despite this, have reason to reject the PFC?

\section{Act and Rule Paretianism}

Suppose individuals make decisions freely, and sign contracts voluntarily. If these contracts have no negative fall out on others, must the state always allow them? As

\footnotetext{
${ }^{14}$ Basu (2000) and Hatlebakk (2002) show that it can be credible.

${ }^{15}$ Nozick (1974, see, especially, p.263) argues that there cannot be coercion if each agent acts "within their rights." What I have just demonstrated is that, even if a person chooses within his rights, by making his
} 
I have already indicated in the opening section, the answer is no; but, at the same time, the negative answer must not be ubiquitous, nor based on whimsy. I shall here develop some principles which can allow us to be Paretians but still, on occasions, violate the PFC.

\subsection{The 'Large Numbers Argument': A Game-theoretic Demonstration}

The principle that I will develop here is what I have elsewhere called the 'large numbers argument' (Basu, 2003), which argues that there are situations where each of a class of actions (exchange contract signing triad) could be morally justified, whereas the whole class of actions may be morally unacceptable. This possibility of morally distinguishing between single acts and a collectivity of a large number of such acts was first put forward by Parfit (1984) ${ }^{16}$. But this raises the question, Is this logically possible? In this section I construct a formal game-theoretic example to show that the answer is yes. This creates a policy conundrum — should such acts be permitted or not? Given that the state often has to go by rules and cannot afford the complication of a case by case consideration, the example in this section could be construed as an argument for rulebased violation of the PFC. I have discussed this in practical, real-life contexts elsewhere (Basu, 2003; Basu and Van, 1998). What follows may be viewed as the construction of a formal analytical foundation for such arguments. I shall return to some practical policy discussions later.

Suppose there is a set $N \equiv\{1,2, \ldots\}$ of individuals, each of whom can either choose a certain strategy or action or not. If we use 1 to denote the strategy of choosing to sign the contract and 0 to denote the strategy of rejecting the contract, then the set of actions open to each person i can be denoted by $\{0,1\}$. The action in question could be the decision to participate in an exchange or sign a contract or trade commodities. Of course, trading or signing a contract typically involves another person. We can get around this by assuming there is a person 0 who is always prepared to trade with everybody in $N$.

choice conditional on what someone else does ("I will trade with you, provided you have boycotted the worker"), it is possible to exercise what on dispassionate analysis will appear to us as coercion.

${ }^{16}$ See also Neeman (1999). An unwitting use of the same idea occurs in Genicot (2002). 
And in order not to let him complicate our analysis I shall suppose his utility never changes. So we really do not have to bring him into the analysis explicitly.

Hence, a strategy tuple or an outcome of this 'game' could be represented by an infinite vector $\mathrm{x} \equiv\left(\mathrm{x}_{1}, \mathrm{x}_{2}, \ldots\right)$, where, for all $\mathrm{i} \in \mathrm{N}, \mathrm{x}_{\mathrm{i}} \in\{0,1\}$ and the value of $\mathrm{x}_{\mathrm{i}}$ denotes whether or not i signed the contract. One possible outcome of this game is $(1,0,1,0,1$, $0, \ldots$ ). This represents the case where every odd numbered person signs the contract and every even numbered person rejects it. I shall use $\Delta$ to denote the set of all strategy tuples or outcomes.

Given a strategy tuple $x$ and a strategy $x_{i}^{\prime}$, I will write $x /\left(x_{i}=x_{i}^{\prime}\right)$ to denote a strategy tuple identical to $x$ excepting that the $i^{\text {th }}$ element is replaced with $x_{i}^{\prime}$. Note that $\left(\mathrm{x} /\left(\mathrm{x}_{\mathrm{i}}=\mathrm{x}_{\mathrm{i}}\right)\right)=\mathrm{x}$.

Next, define player i's payoff or utility function to be a mapping $\mathrm{u}_{\mathrm{i}}: \Delta \rightarrow \mathfrak{R}$, where $\mathfrak{R}$ is the set of real numbers. What I am looking for is a game that has the following properties.

First, whether or not $\mathrm{j}$ decides to sign the contract this has no externality on player $\mathrm{i}(\neq \mathrm{j})$. Formally,

Property 1. For all $\mathrm{i}, \mathrm{j} \in \mathrm{N}, \mathrm{i} \neq \mathrm{j}$, and for all $\mathrm{x} \in \Delta, \mathrm{u}_{\mathrm{i}}\left(\mathrm{x} /\left(\mathrm{x}_{\mathrm{j}}=1\right)\right)=\mathrm{u}_{\mathrm{i}}\left(\mathrm{x} /\left(\mathrm{x}_{\mathrm{j}}=0\right)\right)$.

This means that if the individual wants to sign the contract, this will come under the purview of the PFC. The government should seemingly have no reason to stop this contract.

Next we want the game to illustrate the large numbers argument. That is, it has to have the property that, if a 'large' number of people sign the contract, then others (the non-signers) will be worse off. Formally,

Property 2. There exists a set $\mathrm{S} \subset \mathrm{N}$ and $\mathrm{i} \in \mathrm{N}$ - S, such that if $\mathrm{x}, \mathrm{y} \in \Delta$ such that, for all $\mathrm{j} \in \mathrm{S}, \quad \mathrm{x}_{\mathrm{j}}=0$ and $\mathrm{y}_{\mathrm{j}}=1$ and, for all $\mathrm{k} \in \mathrm{N}-\mathrm{S}, \mathrm{x}_{\mathrm{k}}=\mathrm{y}_{\mathrm{k}}=0$, then $\mathrm{u}_{\mathrm{i}}(\mathrm{y})<\mathrm{u}_{\mathrm{i}}(\mathrm{x})$. 
At first sight Properties 1 and 2 seem irreconcilable. However, what follows is a description of a game that satisfies both these properties and thereby shows that Parfit's moral conundrum is at least a logical possibility ${ }^{17}$.

Let $\ell, h \in \Re$ be such that $\ell<\mathrm{h}$. Now, for all $\mathrm{i} \in \mathrm{N}$, define $\mathrm{u}_{\mathrm{i}}$ as follows:

$$
u_{i}(x)= \begin{cases}\ell+g_{i}\left(x_{i}\right), & \text { if } \sum_{j=1}^{\infty} x_{j}=\infty \\ h+g_{i}\left(x_{i}\right), & \text { if } \sum_{j=1}^{\infty} x_{j}<\infty\end{cases}
$$

where $g_{i}=\{0,1\} \rightarrow \Re$. It is easy to check that if players have payoff functions, as just defined, then Properties 1 and 2 will be satisfied: Consider the utility function of a player i, and some $\mathrm{x} \in \Delta$. If $\sum \mathrm{x}_{\mathrm{j}}=\infty$ then this fact will not change whether or not one player (say k) changes her strategy. Likewise if $\sum \mathrm{x}_{\mathrm{j}}<\infty$. Hence, (1) implies Property 1 must be true. Next, let $\mathrm{S}$ be the set of all odd numbers; and i be an even number. Then Property 2 follows from the fact that $\ell<\mathrm{h}$.

To see some of the policy dilemmas that can arise in this game, consider the case where the payoff functions are as just defined (i.e. by (1)) and, in addition,

and

$$
g_{i}(1)>g_{i}(0) \quad \text { if } i \text { is odd }
$$

$$
\mathrm{g}_{\mathrm{i}}(1)<\mathrm{g}_{\mathrm{i}}(0) \text { if } \mathrm{i} \text { is even. }
$$

Now suppose the players are made to play this game. Clearly the game has a unique Nash equilibrium (which happens to be strict), where only and all odd-numbered players accept the contract, which could, for instance, be for a job which expose them to sexual harassment.

What are the welfare properties of this Nash equilibrium? That depends on the parameters. In particular, the following proposition is easy to verify.

The Nash equilibrium in the above game is Pareto optimal, if, for every $i$ that is an odd number,

\footnotetext{
${ }^{17}$ In general equilibrium theory we do encounter examples of this kind where each individual's choice has no impact on others but a collectivity of such choices can have a perceptible effect. But these are usually formalized for economies with an uncountable set of individuals. What I am about to demonstrate is the possibility of this happening in countable societies. In the next section it is shown that similar results can be obtained even in finite societies, provided that we are willing to relax the assumption of transitivity. To me it is more realistic to think of finite societies with intransitive preferences than uncountably infinite societies with each person having transitivity preferences.
} 


$$
\ell+g_{i}(1)>h+g_{i}(0)
$$

Consider now the outcome in the above game when there is a law that prohibits sexual harassment (that is, everybody is forced to choose strategy 0). Evidently, every player i will now get a utility of $h+g_{i}(0)$. Suppose now that, for every $i$, the inequality in (2) is reversed. Then not only is the Nash equilibrium in a regime where there is no legal prohibition on sexual harassment Pareto sub-optimal but it is Pareto dominated by a regime where sexual harassment is prohibited.

Hence, if we were deciding on whether to prohibit sexual harassment or not, by using any social welfare criterion which happened to respect the Pareto Principle, we would prohibit sexual harassment. Of course, if, starting from such a prohibition, we allowed one odd-numbered agent to sign a harassment contract, we would achieve a further Pareto improvement; but if we started this 'opportunistic' adjustment of the law to allow for 'exceptions' whenever such an exception resulted in a Pareto improvement, we would end up in a state which is Pareto inferior to what would prevail in a regime of a total prohibition. ${ }^{18}$ This is a paradoxical sounding result but it is germane to the construction of a principle for banning sexual harassment and some other labor market practices, such as exposure to excessive hazards.

\subsection{Quasi-Transitivity and the Large Numbers Argument}

It was demonstrated in Section 3.1 that the moral status of each single act or contract may be different from the moral status of a class of such acts or contracts. Some may however object to this demonstration on the ground that it was based on the existence of an infinite number of potential contracts. Indeed some may consider the realism of the economist's model of competitive general equilibrium to be suspect because of the assumption that the action of each individual has no effect on market

\footnotetext{
18 This game has some structural similarity to what was described as 'Escher's Waterfall' game in Basu (1994), where a steady stream of downward movement nevertheless ends up at a higher perch. For some similar paradoxes and some deep insights into how to resolve them see Arntzenius, Elga and Hawthorne (2004). All their examples, however, entail infinite choices and therefore differ from what I am about to illustrate in the next section, to wit, that similar 'paradoxes' can occur even in finite decision contexts.
} 
variables, such as prices, but the action of a collection of individuals does have an effect. ${ }^{19}$

It will be argued here that the problem of infinity is avoidable if we relax the usual assumption of human preferences being transitive and allow individuals to have quasi-transitive preference, instead. A person's preference is said to be 'quasi-transitive' if, whenever he prefers $\mathrm{x}$ to $\mathrm{y}$ and prefers $\mathrm{y}$ to $\mathrm{z}$, it is also the case that he prefers $\mathrm{x}$ to $\mathrm{z}$. The important aspect in which transitivity of preference differs from quasi-transitivity is that the latter does not require the indifference relation to be transitive. Hence, a person with quasi-transitive preference may be indifferent between $\mathrm{x}$ and $\mathrm{y}$ and between $\mathrm{y}$ and $\mathrm{z}$ but prefer $\mathrm{x}$ to $\mathrm{z}$.

Though most social scientists are trained to believe otherwise, a little introspection shows that the transitivity of indifference is a remarkably unrealistic assumption. ${ }^{20}$ Most people will be indifferent between a cup of coffee with 1 grain of sugar and a cup of coffee with 2 grains of sugar; and, more generally between a cup with $n$ grains and a cup with $n+1$ grains. But they will not be indifferent between $n$ grains and $n+m$ grains, when $m$ is sufficiently large.

Recognizing this is a good way to reconcile two standard assumptions of the competitive market model, namely, that an individual's action does not affect another person's welfare and that the actions of a collection of individuals may well effect the welfare of someone not belonging to this collection.

I shall however here use the assumption of quasi-transitivity not in a competitive model but in a game model. Return to Section 3.1 and all the way to the definition of a strategy tuple. But now assume, first, that the set of players is $\overline{\mathrm{N}}$ and this is finite and second that, instead of a utility function, individuals are endowed with preference relations. Let $\# \overline{\mathrm{N}}=\mathrm{k}$ and $\bar{\Delta}$ be the collection of all $\mathrm{k}$-tuple of strategies. Hence, $\left(\mathrm{x}_{1}, \ldots, \mathrm{x}_{\mathrm{k}}\right) \in \bar{\Delta}$, where $\mathrm{x}_{\mathrm{i}} \in\{0,1\}$.

\footnotetext{
${ }^{19}$ For an interesting discussion of the philosophical basis of this assumption, especially its relation to methodological individualism, see Arrow (1994), Bhargava (1995). Philosophical objections to the use of infinity to model 'large number' was stressed to me by David Lewis (personal communication dated January 15, 1990).

${ }^{20}$ There is a small literature that points this out. See, for instance, Majumdar (1958), Fishburn (1970).
} 
Formally, every player $\mathrm{i} \in \overline{\mathrm{N}}$ is endowed with a binary preference relation $\succ_{i_{i}}$ on $\bar{\Delta}$. That is, $\succ_{\sim \mathrm{i}} \subset \bar{\Delta} \times \bar{\Delta}$ and $(\mathrm{x}, \mathrm{y}) \in \underset{\sim \mathrm{i}}{\succ}$, which may also be written as $\mathrm{x} \underset{\sim \mathrm{i}}{\succ_{1}}$ y, is to be interpreted as 'player i finds strategy tuple $\mathrm{x}$ to be at least as good as strategy tuple y. For notational simplicity I shall, henceforth, denote the symmetric and asymmetric parts of $\succ_{\mathrm{i}}$ by, respectively, $\sim_{\mathrm{i}}$ and $\succ_{\mathrm{i}}$. It is assumed throughout that, for all $\mathrm{i} \in \overline{\mathrm{N}}, \succ_{\mathrm{i}}$ is reflexive $(\forall \mathrm{x} \in \bar{\Delta}, \mathrm{x} \underset{\sim \mathrm{i}}{\succ} \mathrm{x})$, complete $\left(\forall \mathrm{x}, \mathrm{y} \in \bar{\Delta}\right.$, where $\mathrm{x} \neq \mathrm{y}, \mathrm{x} \succ_{\mathrm{i}_{\mathrm{i}}} \mathrm{y}$ or $\left.\mathrm{y} \succ_{\sim \mathrm{i}} \mathrm{x}\right)$ and quasi-transitive $\left(\forall \mathrm{x}, \mathrm{y}, \mathrm{z} \in \bar{\Delta}, \mathrm{x} \succ_{\mathrm{i}} \mathrm{y}\right.$ and $\mathrm{y} \succ_{\mathrm{i}} \mathrm{z}$ implies $\left.\mathrm{x} \succ_{\mathrm{i}} \mathrm{z}\right)$.

For all $\mathrm{i} \in \overline{\mathrm{N}}$, let us use $\mathrm{D}_{\mathrm{i}} \subset \bar{\Delta} \times \bar{\Delta}$ to denote the set of all pairs (x,y) which are 'i-variants'. That is, $(x, y) \in D_{i}$ if and only if $\forall j \neq i, x_{j}=y_{j}$.

Now, we are ready to impose some properties on individual preferences.

Property 3. If $(x, y) \in D_{i}$ and $j \neq i$, then $x \sim_{j} y$.

This simply formalizes the standard assumption of no externality in competitive markets. That is, whether or not i signs the contract (whether it be contract for a job in which there may be sexual harassment or exposure to excessive health hazards), person $\mathrm{j}$ $(\neq \mathrm{i})$ perceives no welfare change for herself. Property 3 is the counterpart of property 1 in the absence of a utility function.

Next consider:

Property 4. There exist an integer $n>1, i \in N$ and $\left\{x^{1}, x^{2}, \ldots, x^{n+1}\right\} \subset \bar{\Delta}$ such that, $\forall \mathrm{m} \in\{1, \ldots, \mathrm{n}\},\left(\mathrm{x}^{\mathrm{m}}, \mathrm{x}^{\mathrm{m}+1}\right) \in \mathrm{D}_{\mathrm{j}}$, for some $\mathrm{j} \in \overline{\mathrm{N}}-\{\mathrm{i}\}$, where $\mathrm{x}_{\mathrm{j}}^{\mathrm{m}}=0, \mathrm{x}_{\mathrm{j}}^{\mathrm{m}+1}=1$, and $\mathrm{x}^{1}$ $\succ_{\mathrm{i}} \mathrm{X}^{\mathrm{n}+1}$

If $\succ_{\sim}$ were transitive Properties 3 and 4 would not be compatible; but the quasitransitivity of $\succ_{i}$ makes the two properties compatible in an obvious way. 
What property 4 says is that if a large number of people sign such contracts this can cause a perceptible difference for the worse in the economic environment for some individuals $\mathrm{i}$.

Let us now analyze the possible outcomes of this 'game'. I write 'game' within inverted commas to remind the reader that these are games with no payoff functions but binary preference relations over the outcomes, where the preference relations are reflexive, complete and quasi-transitive. There is a substantial literature in economics on aggregating quasi-transitive individual preferences (see, for instance, Sen and Pattanaik, 1969; Pattanaik, 1970; Fishburn, 1970). But there is very little on 'games' with quasitransitive individual preferences.

To see the kind of results we can get, consider the case where $\mathrm{k}=3$ and Property 4 is true for $n=2$. In addition to Properties 3 and 4, assume the following is true: For all $\mathrm{i} \in \overline{\mathrm{N}}$, if $(\mathrm{x}, \mathrm{y}) \in \mathrm{D}_{\mathrm{i}}$, and $\mathrm{x}_{\mathrm{i}}=1, \mathrm{y}_{\mathrm{i}}=0$, then $\mathrm{x} \succ_{\mathrm{i}} \mathrm{y}$. In other words, other things remaining the same, each person prefers to sign such a contract.

In this 'game', the Nash equilibrium is clearly given by $(1,1,1)$. However, we can think of individual preferences compatible with Properties 3 and 4, which imply that each individual prefers $(0,0,0)$ to $(1,1,1)$. Let us assume that this is the case. Then $(0,0,0)$ Pareto dominates $(1,1,1)$. Hence, if a government committed to the Pareto criterion has to choose between a law disallowing sexual harassment or prohibiting excessive workplace hazards (whatever happens to the example we are considering), and no such law, it should opt for having such a law.

Suppose such a law is in place and so the outcome is $(0,0,0)$. It is easy to see that $(1,0,0)$ is Pareto superior to $(0,0,0)^{21} ;(1,1,0)$ is Pareto superior to $(1,0,0)$; and $(1,1,1)$ is Pareto superior to $(1,1,0)$. Hence, this game has no Pareto optimal outcome. Therefore, we no longer have a compelling case that if a change is a Pareto improvement, it must be allowed, since by the repeated use of this criteria we would end up at a Pareto inferior outcome.

One way of overcoming this problem is to override consumer sovereignty and work with what may be described as each consumer's 'subliminal preference', that is, an

\footnotetext{
${ }^{21}$ This is because person 1 prefers this by assumption and, since an individual's action has no externality, others are indifferent.
} 
ordering which may be thought of as the 'true' preference underlying a person's selfperceived preference, that is, the preference that we have been talking about all this time. More formally, given a person's (self-perceived) preference relation, š, the set of possible subliminal preferences that could have generated š is defined by

$$
S(\check{S})=\left\{R^{*} R \text { is an ordering such that, for all } x, y, x^{T M} y Y x P y,\right.
$$

where ${ }^{\mathrm{TM}}$ is the asymmetric part of $\check{\mathrm{S}}$ and $\mathrm{P}$ is the asymmetric part of R.

Since Š $0 \mathrm{~S}(\check{S})$ implies that $\check{\mathrm{S}}$ is an ordering, the (self-perceived) preference relations that we have been considering above cannot be subliminal. Now, if we maintain that social decisions ought to be based on individuals' subliminal preferences, then in the above example the Pareto deadlock gets broken. It is now easy to see that in the above example, given individual preferences as described, the only outcome that cannot be Pareto optimal under any subliminal preference triple (that is, for the three players) is $(1,1,1)$. If in addition we prefer to treat players symmetrically, the game being fully symmetric, the preferred outcome must be $(0,0,0)$, justifying once again a ban on the contract, even though consenting adults may knowingly want to sign such contracts. It is however, worth emphasizing that this entails over-ruling consumer sovereignty, that is, the expression of individual preferences as perceived by the individuals themselves.

\subsection{Acts and Rules}

The games in section 3.1 and 3.2 illustrate the conflict between actconsequentialism and rule-consequentialism. Consider the above 3-player game, and assume that a moral agent, committed to any Pareto-inclusive consequentialist ethic, has to recommend each player's choice of action or strategy. If this moral agent were an actconsequentialist, he would recommend to each agent seeking his advice that she choose action 1 over 0 . Hence, the social outcome will be $(1,1,1)$.

However, suppose the moral agent, using the same moral principle as the above one but committed to rule-consequentialism, has to opt between the following two rules. Rule 1: Whenever a person faces a choice between signing a sexual harassment contract (action 1 ) and not signing it (action 0 ), she should choose action 0 . Rule 2: Whenever a 
person faces a choice between action 1 and action 0 , she should choose action 1. Clearly, he will opt for Rule 1 . Hence, the social outcome will be $(0,0,0)$.

Since $(0,0,0)$ is strictly Pareto preferred to $(1,1,1)$, the above example shows that not only does rule-consequentialism differ from act-consequentialism but it can lead to a Pareto-superior choice. It is noteworthy that the argument for banning certain voluntary transactions is here founded in consequentialism (albeit rule consequentialism). There is no resort to deontological ethics as is often the case when intervening in people's free choice.

The large numbers argument—namely, the ability to morally differentiate single acts and a large number of such acts (without abandoning the Pareto principle) — helps us analyze several practical policy matters ${ }^{22}$. It can provide foundation to why we may wish to outlaw the 'yellow dog' contract as is done by the Norris-La Guardia Act, 1932, in the United States. It could be argued that, if one worker prefers to give up her right to join trade unions in order to get a certain job that demands this of her, then this may be a Pareto improvement. But if such yellow dog contracts are made legal, then lots of firms will offer such contracts, and the terms for jobs without a yellow-dog clause may deteriorate so much that those who are strongly averse to giving up the right to join unions will be worse off in this world. Of course, we have to construct a model and show that this is true in realistic economic scenarios. All that I have done here is to demonstrate that this is logically possible, even in finite societies. Once this has been done, we can clearly distinguish between allowing a single worker and a single employer signing such a contract and legalizing such contracts in general.

To make my task harder I have concentrated in this paper on actions or contracts, which seem to make some people better off without making anybody worse off. But the large numbers argument can be carried over to other contexts as well. There is currently a debate raging in the U.S. as to whether the state should legalize the use of torture to

\footnotetext{
${ }^{22}$ It also sheds light on an important individual decision problem that was highlighted by Schelling (1985). There are situations, he argued, where one needs to have "rules for oneself." We can think of rules like, I must have no more than 4 drinks or I must not wade further than 10 yards into the shark infested sea and so on. He argued, without formalizing, that there are situations where a tiny bit more may always be desirable but $\mathrm{n}$ tiny bits more may not be. At first sight this is a paradoxical claim. But the algebra of my analysis can be viewed as a possible formalization of this claim.
} 
extract information from prisoners. In a recent newspaper article, Anne Kornblut ${ }^{23}$ presents the pros and cons of the argument of Charles Krauthammer that the use of torture in limited situations should be legalized. He tries to persuade by constructing extreme examples such as a bomb has been planted by a terrorist, which will kill a million people. The terrorist will give you information that will allow you to defuse the bomb only if you torture him. He argues that it is morally incumbent on us to torture him. I can see that many people would agree that this person should be tortured, though it is not clear to me why he takes the example of the terrorist needing to be tortured. What if the bomb has been planted by a terrorist but the only way to get the information is by torturing a nice little boy who however will not speak unless he is tortured.

But the point that Krauthammer misses is that the fact that he can create examples where torture would be justified is not equivalent to a case for legalizing torture. Legalizing torture immediately refers to a class of situations. There may be plenty of reason not to enshrine torture into law, even though that means that our hands will be tied in some special cases where we may have reason to use torture.

Return to the case of sexual harassment in the workplace or the problem of hazardous work. To justify banning hazardous work, for instance, by using the 'large numbers argument' entails a very different kind of reasoning than what is popularly used to justify such bans. The case for a ban here does not rest on the fact that the worker's health will be harmed. If the worker is willing to take that harm for the extra money that he will get, we have no moral jurisdiction over this to stop him. Hence, we must not treat the worker whose health is damaged as the victim and have the courts act on his behalf, though that is typically what is done. The large numbers argument points to the fact that many workers accepting such contracts may have a negative welfare impact on other workers - for instance, those who have especially strong aversion to hazardous work and that becomes the real basis of why we may wish to disallow such contracts. This is not a standard case of externality since the signing of each such contract has no effect on other workers. It is only the signing of a class of such contracts that has this effect.

\footnotetext{
${ }^{23}$ See, for instance, Anne Kornblut, 'He Says Yes to Legalized Torture,' New York Times, December 11, 2005, Section 4, p.1 \& 4.
} 
For economic theorists it is interesting to note that if we are to demonstrate this in a finite-population economy, then we have to allow for the fact that individuals may fail to satisfy transitivity of indifference. While there is a lot of work on intransitive preferences in economics, modeling market equilibria with individuals who have quasitransitive preferences is quite rare.

\section{Multiple Equilibria}

Another general argument for disregarding the PFC occurs in economies in which there is more than one equilibrium. Suppose an economy has two competitive equilibria. By a standard theorem in welfare economics and general equilibrium theory ${ }^{24}$ we know that each of these equilibria has to be Pareto optimal. That being so, neither equilibrium can be Pareto superior to the other ${ }^{25}$. Keeping this in mind, consider imposing a ban that prevents one particular equilibrium from being realized and deflects the economy to the other equilibrium. In that case the ban cannot be denied on the ground that it will cause a Pareto worsening. This is the argument that was used by Basu and Van (1998) to justify banning child labor in some situations ${ }^{26}$. It was first demonstrated that some economies are likely to have more than one equilibria, in particular, one equilibrium in which wages are low and households send their children to work and another in which wages are high and children do not work. In case the country is caught in the former equilibrium, a ban on child labor can be justified or, more minimally, a ban cannot be denied on grounds of the Pareto principle.

A single child not being allowed to work will of course hurt the child's welfare, since typically it is poverty that drives children to work and stopping one child from

\footnotetext{
${ }^{24}$ The First Fundamental Theorem of Economics. This is often viewed as a formalization of Adam Smith's idea of the 'invisible hand.'

${ }^{25}$ Once we move away from the competitive market to strategic environments indeed one equilibrium can Pareto dominate another. One may be tempted to presume in such economies individuals will naturally choose the Pareto dominant outcome. But introspection suggests and experiments show that in games with large numbers of players it is quite common to get trapped in the inferior equilibrium (see Cooter and Bohnet, 2001). In that case, the justification for legal intervention (for instance, that of taxing or banning the inferior action) is immediate.

${ }^{26}$ While I prefer to remain within a welfarist-consequentialist framework in addressing the possibility of legislative bans on child labor, for some deep and intriguing arguments that go beyond welfarism, see Satz (2003).
} 
working would have a negligible effect on adult wages and therefore on the households' poverty. But when a general legislative ban is put in place, all children will be forced to leave work. The unfilled demand for labor caused by this will push up adult wages and it is entirely possible that in the new equilibrium children will be better off. Once again behind this is the large numbers argument. But in general equilibrium we usually assume this - that one buyer or seller has no impact on prices but a collectivity does. The formal analysis sheds light on how we can actually achieve this in a finite or a countable society.

This argument could potentially apply to other matters of labor market regulation. But one will have to analyze theoretically and empirically and see if it does actually apply to each particular case. One ancient problem on which this has been used to shed light is to do with statutory limit on work hours (Raynauld and Vidal, 1998; Singh, 2003). Should the law be used to set a limit on the maximum number of hours a worker is allowed to work? At first sight the answer seems to be no, by the $\mathrm{PFC}^{27}$. If an employer wants a worker to work for 14 hours a day and there is a worker willing to work that many hours, there is no reason why government should get in the way. But note that one reason why workers may wish to work that many hours is if the hourly wage rate is low. Reasons of subsistence could then drive them to work hard. Now, a statutory limit on work hours can, by limiting the supply of labor, push up the hourly wage rate; and it is possible that at this higher wage rate people would not want to work that many hours. In other words, the labor market may have two or more equilibria, in which case banning the long-hours equilibrium is fully compatible with a commitment to the Pareto principle $^{28}$.

There are other problem areas of labor-market intervention where it is not evident whether any of these arguments apply. But at least now we know what to look for if we are to ban some form of voluntary contract without abandoning the Pareto principle.

One such problem, that is a source of some concern to the International Labor Organization, is that in some developing countries workers, who wish to work in an

\footnotetext{
${ }^{27}$ This is the view that was taken by the U.S. Supreme Court in the Lochner v. New York, 1905, case.

${ }^{28}$ In the presence of multiple equilibria which do not Pareto dominate one another, a different justification for intervention that has to do with justice and fairness is to have rules for moving from one equilibrium to another depending on the context. A society may decide that on sunny days the outcome should be one where player 1 gains the most and on rainy days the outcome should be one where player 2 gains the most. Justice, by this argument, is a method for selecting between different equilibria (Myerson, 2004).
} 
export processing zone (EPZ) or in a maquiladora, are being asked to give up their right to collective bargaining as a condition for being allowed to work for an EPZ-based firm. The principle of free contract seems to suggest that it is fine to ask workers to do so, since no one coerces a worker to work in an EPZ. If a worker is willing to give up the right to bargain collectively in order to work in an EPZ, there must be other benefits that make this worthwhile to the worker.

At this stage this argument seems quite compelling. If we are to stop the use of such yellow dog contracts in export processing zones, we cannot leave this to some arbitrary hand-waving justification or an opportunistic resort to some deontological ethic. We need to construct a formal argument founded on some prior ethical principles. What this paper has done is to highlight where those arguments may come from. We basically have to see if the large numbers argument or the multiple-equilibria argument applies to this problem. If it does not, we will have to treat this as a case where free contracting has to be allowed. If this means that workers will be asked to leave their right to collective bargain at the doorstep of EPZs, then we have to put up with that. To do otherwise would likely lead to a Pareto worsening and this would hurt the very workers we are trying to protect.

\section{Epilogue}

Market fundamentalists, who would leave it all to individuals pursuing their own selfish ends, in the belief that the invisible hand invariably guides society to some collectively optimal state are getting Adam Smith wrong and economic theory wrong. There are cases where one needs the visible hand of the state to stop market transactions. The standard justification for this in economics is externality. But what if there is no observable externality on uninvolved third parties? For many economists that means there is no further justification for government intervention. This leaves us with many difficult cases - voluntary slavery, sexual harassment where the possibility of this is made clear to workers before they sign up to work, hazardous work, trade in body parts.

Faced with these troublesome questions many clutch at whatever opportunistic ethic that is available on hand. This is risky, especially in today's globalized world where 
we may wish to enact laws for distant nations or get into collective conventions that are enforced on all countries. For well-meaning activists in industrialized nations it is easy to err on the opposite side of the market-fundamentalist economist by seeking to ban a variety of labor market contracts that in the context of a developed nation may well be justified. It is easy to forget that to stop a very poor worker from working in hazardous conditions may be to condemn him and his family to starvation, that to simply legislatively ban child labor under all circumstances may risk sending children to prostitution and causing malnourishment. In the contemporary world of free-flowing capital and goods, interventions to stop contracts, exchanges and trade that are voluntarily made with no obvious negative externality on others need to be founded on appealing prior ethical principles. I would go further and argue that the Pareto principle, which says that between two states of the world if there is one where no one is worse off and someone is better off then that state should not be thwarted from coming into existence. The aim of this paper was to outline some fundamental criteria that could be used to decide if a particular contract should be allowed or not.

It was shown how these criteria apply naturally to some specific problems-for instance, child labor and the use of statutory limits on work hours. But there are other problems where they either do not apply or we do not as yet know if they apply. These have to remain on our research agenda. But by trying to base our interventions on wellfounded underlying principles we can at least hope to eliminate arbitrary but wellmeaning interventions and, more importantly, the risk that small powerful lobbies with their own selfish interests will hijack the policies of governments and international organizations. 


\section{References}

Akerlof, George (1976), 'The Economics of Caste and the Rat Race and Other Woeful Tales,' Quarterly Journal of Economics, vol. 90.

Arntzenius, Frank, Elga, Adam and Hawthorne, John (2004), 'Bayesianism, Infinite Decisions, and Binding,' Mind, vol. 113.

Arrow, Kenneth (1994), 'Methodological Individualism and Social Knowledge,' American Economic Review, vol. 84.

Basu, Kaushik (1994), 'Group Rationality, Escher's Waterfall and Utilitarianism,' Games and Economic Behavior, vol. 7.

Basu, Kaushik (2000), Prelude to Political Economy: A Study of the Social and Political Foundations of Economics, Oxford: Oxford University Press.

Basu, Kaushik (2003), 'Economics and Law of Sexual Harassment in the Workplace,' Journal of Economic Perspectives, vol. 17.

Basu, Kaushik (2005), 'Gender and Say: A Model of Household Decision-making with Endogenous Balance of Power,' Economic Journal, forthcoming.

Basu, Kaushik and Mitra, Tapan (2003), 'Aggregating Infinite Utility Streams with Intergenerational Equity: The Impossibility of Being Paretian,' Econometrica, vol. 71.

Basu, Kaushik and Van, Pham Hoang (1998), 'The Economics of Child Labor,' American Economic Review, vol. 88.

Bhargava, Rajeev (1995), Individualism in Social Science: Forms and Limits of Methodology, Oxford: Oxford University Press.

Choi, Stephen and Gulati, Mitu (2005), 'Contract as Statute,' mimeo: New York University and Georgetown University.

Cohen, Gerry (1986), 'Self-Ownership, World-Ownership, and Equality,' in Frank Lucash (ed.), Justice and Equality Here and Now, Ithaca: Cornell University Press. 
Cohen, Gerry (1987), ‘Are Disadvantaged Workers Who take Hazardous Jobs Forced to take Hazardous Jobs?', in Gertrude Ezorsky (ed.), Moral Rights in the Workplace, Albany: SUNY Press.

Cooter, Robert and Bohnet, Iris (2001), ‘Expressive Law: Framing or Equilibrium Selection?' mimeo: University of California, Berkeley.

Deshpande, Ashwini (1999), 'Loan Pushing and Triadic Relations,' Southern Economic Journal, vol. 65.

Farber, Daniel (2005), 'The Problematics of the Pareto Principle,' Express Preprint Series, Paper 698. Berkeley Electronic Press.

Fishburn, Peter (1970), 'Intransitive Indifference in Preference Theory: A Survey,' Operations Research, vol. 18.

Friedman, Milton (1962), Capitalism and Freedom, Chicago: Chicago University Press. Gaertner, Wulf, Pattanaik, Prasanta and Suzumura, Kotaro (1992), 'Individual Rights Revisited', Economica, vol. 59, 161-77.

Genicot, Garance (2002), 'Bonded Labor and Serfdom: A Paradox of Voluntary Choice', Journal of Development Economics, vol. 67.

Hatlebakk, Magnus (2002), 'A New and Robust Subgame Perfect Equilibrium in a Model of Triadic Power relations,' Journal of Development Economics, vol. 68.

Iversen, Vegard (2004), 'On Notions of Agency, Individual Heterogeneity, and the Existence, Size, and Composition of a Bonded Child,' in Stephen Cullenberg and Prasanta Pattanaik (eds.) Globalization, Culture, and the Limits of the Market: Essays in Economics and Philosophy, New Delhi: Oxford University Press.

Kanbur, Ravi (2004), 'On Obnoxious Markets,' in Stephen Cullenberg and Prasanta Pattanaik (eds.) Globalization, Culture, and the Limits of the Market: Essays in Economics and Philosophy, New Delhi: Oxford University Press.

Kaplow, Louis and Shavell, Steven (2001), 'Any Non-Welfarist Method of Policy Assessment Violates the Pareto Principle,' Journal of Political Economy, vol. 109, 281-6.

Kaplow, Louis and Shavell, Steven (2002), Fairness and Welfare, Cambridge, MA: Harvard University Press. 
Korobkin, Russell (2003), ‘Bounded Rationality, Standard Form Contracts and Unconscionability,' Univesity of Chicago Law Review, vol. 70

Macpherson, C. B. (1973), Democratic Theory: Essays in Retrieval, Oxford: Clarendon Press.

Majumdar, Tapas (1958), The Measurement of Utility, London: Macmillan.

Mill, John Stuart (1848), Principles of Political Economy. All references are to the 1970 edition, Harmondsworth: Penguin.

Mill, John Stuart (1859), On Liberty. All references are to the 1971 edition, as part of Utilitarianism, Liberty and Representative Government, London: Dent and Sons.

Myerson, Roger (2004), 'Justice, Institutions, and Multiple Equilibria,' Chicago Journal of International Law, vol. 5, 91-107.

Naqvi, Nadeem and Wemhoner, F. (1995), 'Power, Coercion and the Games that Landlords Play,' Journal of Development Economics, vol. 47.

Neeman, Zvika (1999), 'The Freedom to Contract and the Free-Rider Problem', Journal of Law, Economics and Organization, vol. 15, 685-703.

Nozick, Robert (1969), 'Coercion,' in Sidney Morgenbesser et al (eds.), Philosophy, Science and Method, New York; St. Martin's Press.

Nozick, Robert (1974), Anarchy, Utopia and State, Oxford: Blackwell Publishers.

Otsuka, Michael (1998), 'Self-Ownership and Equality: A Lockean Reconciliation,' Philosophy and Public Affairs, vol. 27.

Parfit, Derek (1984), Reasons and Persons, Oxford: Clarendon Press.

Pattanaik, Prasanta (1970), 'On Social Choice with Quasi-Transitive Individual Preferences', Journal of Economic Theory, vol. 2, 267-75.

Raynauld, Andre and Vidal, Jean-Pierre (1998), Labor Standards and International Competitiveness, Northhampton: Edward Elgar.

Satz, Debra (2003), ‘Child Labor: A Normative Perspective,' World Bank Economic Review, vol. 17.

Satz, Debra (2004), 'Noxious Markets: Why Should Some Things not be for Sale?', in Stephen Cullenberg and Prasanta Pattanaik (eds.) Globalization, Culture, and 
the Limits of the Market: Essays in Economics and Philosophy, New Delhi: Oxford University Press.

Schelling, Thomas (1985), 'Enforcing Rules on Oneself,' Journal of Law, Economics and Organization, vol. 1.

Sen, Amartya (1970a), ‘The Impossibility of a Paretian Liberal,’ Journal of Political Economy, vol. 78.

Sen, Amartya (1970b), Collective Choice and Social Welfare, Edinburgh: Oliver and Boyd.

Sen, Amartya (1973), On Economic Inequality, Oxford: Clarendon Press.

Sen, Amartya (1982), 'Rights and Agency,' Philosophy and Public Affairs, vol.

Sen, Amartya and Pattanaik, Prasanta (1969), 'Necessary and Sufficient Conditions for Rational Choice under Majority Decision, ‘ Journal of Economic Theory, vol. 1.

Singh, Nirvikar (2003), 'The Impact of International Labor Standards: A Survey of Economic Theory,' in K. Basu, H. Horn, L. Roman and J. Shapiro (eds.), International Labor Standards, Oxford: Blackwell Publishers.

Steiner, Hillel (1994), An Essay on Rights, Oxford; Blackwell Publishers.

Sunstein, Cass (1997), Free Markets and Social Justice, Oxford: Oxford University Press.

Trebilcock, Michael (1993), The Limits of Freedom of Contract, Cambridge, MA: Harvard University Press.

Vallentyne, Peter (2000), 'Introduction: Left-Libertarianism - A Primer,' in Peter Vallentyne and Hillel Steiner (eds.) Left-Libertarianism and Its Critics: The Contemporary Debate, New York: Palgrave.

Villanger, Espen (2004), 'Company Influence on Foreign Aid Disbursement: Is Conditionality Credible with Donors Having Mixed Motives?' Southern Economic Journal, vol.

Villanger, Espen (2005), ‘Company Interests and Foreign Aid Policy: Playing Donors out against Each Other,' European Economic Review, forthcoming.

Wertheimer, Alan (1996), Exploitation, Princeton: Princeton University Press.

Zimmerman, David (1981), 'Coercive Wage Offers,' Philosophy and Public Affairs, vol. 10 . 